\title{
Study of Processes and Equipment of the Modern Food and Medicaments Sonochemistry
}

\author{
S. Shestakov ${ }^{1}$, O. Krasulya ${ }^{1}$, B. Krasulya ${ }^{2}$, R. Rink ${ }^{3}$ \\ ${ }^{1}$ Moscow State University of Technology and Management, Moscow \\ ${ }^{2}$ MV Lomonosov Moscow State University, Moscow \\ ${ }^{3}$ Oil Tech Production OY, Tallinn
}

\begin{abstract}
The article described to the study of reactions initiated by cavitation that affect the interaction between the molecules of solutions through hydrogen bonds. They can be attributed to applied sonochemistry, and when it comes to the solutions, which are used in food processing or in medicines - to the food and medicaments sonochemisty. Such reactions do use of sonochemistry in the food industry is safe if taken to prevent the formation in water during cavitation the oxidants such as hydrogen peroxide. This can be achieved if prevented of reactions in the gas phase inside the cavitation bubbles or remove oxygen of air from the solution. A process suppression of unwanted reactions without sacrificing performance sonochemical equipment is described.
\end{abstract}

Keywords - Cavitation, Sonochemistry

\section{INTRODUCTION}

Sonochemistry as area of science is the section of chemistry of high energy. The method of a sonochemistry allows to enhance interaction reagents in endothermic liquid-phase reactions and not demand heating all solution of the reagents. Major factor of sonochemical reactions is acoustic cavitation which generates huge impulses of pressure in liquid from a pulsation of cavitational bubbles. Bubbles in a phase of compression to shrinks to the nanometer sizes, and the steam-gas mix in them is warmed to high temperatures and passes to a condition of plasma which is accompanied by emission of quanta of light and is called a sonoluminescence. These quanta can reach energy of the ultraviolet. Are known even attempts to carry out in the cavitational bubbles, which filled with vapors of acetone with atoms of a deuterium, the inertial thermonuclear synthesis [1]. The modern food sonochemistry investigates influence of cavitation on ability of water to hydration and dissociation of solutes. Hydration, unlike hydrolysis, isn't accompanied by dissociation of molecules, but the modern science is inclined to carry it to chemical reactions since water molecules, which having polarity, cause dissociation on ions of the substances dissolved in it. Using such approach limiting area of a food sonochemistry by reactions, directed on a dipole - dipolar and an ion - dipolar interactions in water solutions, researches in this area are conducted for the last years at Institute of Technological Management of MGUTM.
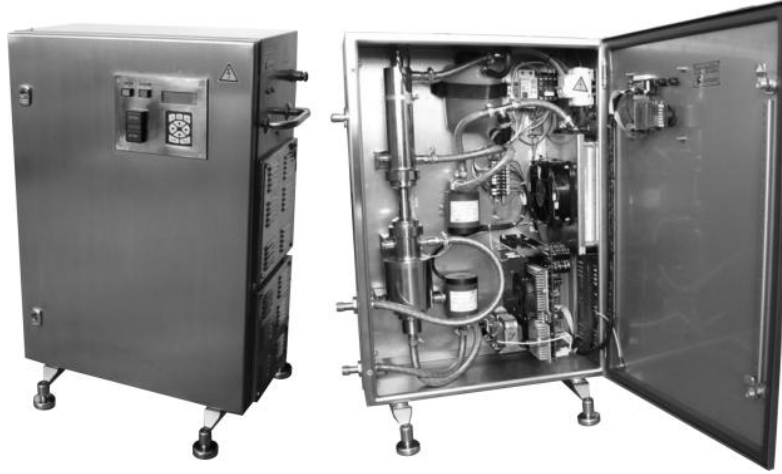

Fig 1. Installation of processing of solutions of the substances used in products from chopped meat

There unique methods of researches of sonochemical processes and devices, and also technologies of cavitational impact on food and medicament environments and sonochemical reactors are developed for their implementation. In 2010 the state sanitary and epidemiologic examination and certification of cavitational reactors of a special series for realization of sonochemical technologies in the food industry is successfully complete. Federal Service for Supervision of Consumer Rights Protection and Human Welfare of Russia these reactors with power from 0,4 to $4,0 \mathrm{~kW}$ allowed for production for use as a part of technological equipment of the food industry and certificate of conformity is issued (Fig 1). 
In 2011 of MSUTM visited one of leading world researchers of sonochemistry the professor of he Melbourn university doctor M. Ashokkumar (Fig 2). He positively noted the approach undertaken by the Moscow colleagues to problems of a food sonochemistry, highly appreciated their researches and took in them a part $[2,3]$.

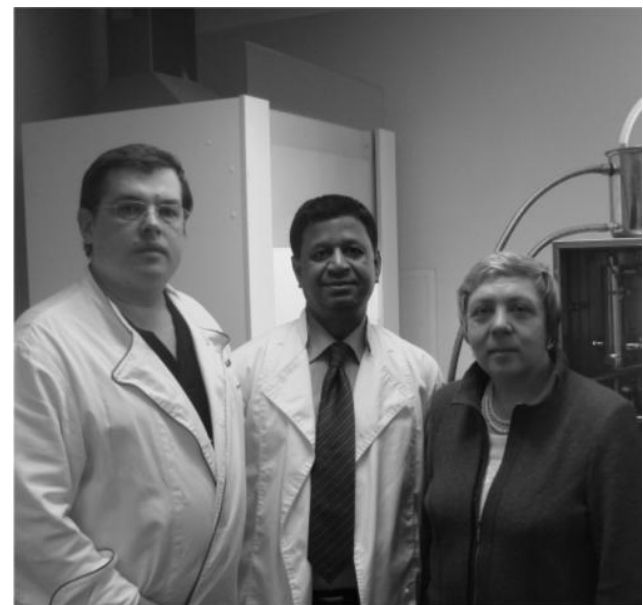

Fig 2. Associate professor V. Bogush, professor M. Ashokkumar and professor O. Krasulya at the laboratory installation used for researches in Moscow.

\section{APPROACH TO APPLIED SONOCHEMISTRY IN RUSSIA}

It was accepted to consider truly sonochemistry only processes in a gas phase in cavitational bubbles [4]. One reactions of the water, which is not accompanied the dissociation of her molecules - destruction by pressure impulses from a pulsation of bubbles of own molecular structure formed by hydrogen communications - incommensurably exceeds by weight of participating reagents pyrolysis reactions in a steam-gas phase of bubbles. Existence of this structures (Fig 3), which reminding structure of ice even at the room temperature that was once again confirmed with researches of Leiden university [5], also is caused by polarity of molecules of water.

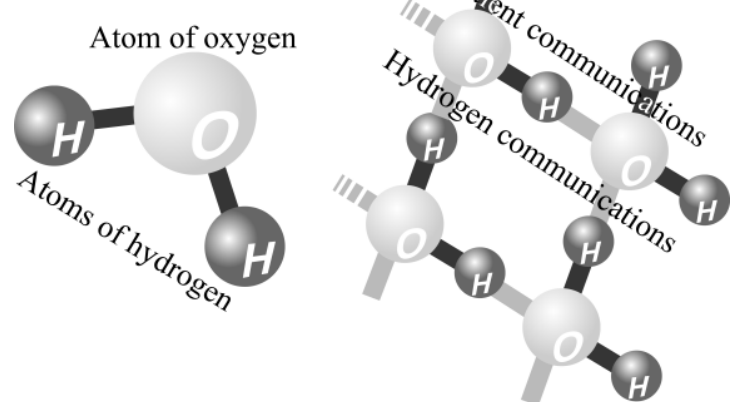

Fig 3. Molecular structure of water, which is formed its hydrogen communications.

As a result of this sonochemical reaction the water for a while loses structure and passes to thermodynamic nonequilibrium condition (Fig 4). At Institute of chemical physics of the Russian Academy of Sciences for the purpose of establishment of duration of process of return to equilibrium was performed of measurements proton magnetic relaxation in the distilled water, which was subjected to sonochemical processing in the cavitational reactor.

She is show existence in water after processing of phases with the differing molecular mobility, the separate existence of which was observed during 2-3 hours. During this period the energy of cavitation is received by water is transformed to warmth of hydration of its molecules itself, that is the warmth which is distinguishing at restoration of hydrogen communications in quantity, corresponding to thermodynamic balance. The strong increase in the viscosity of water as the temperature decreases, a paradoxical decrease in density when cooled below $+4{ }^{\circ} \mathrm{C}$, and high in comparison with non-polar liquids, the surface tension is explained with phenomenon the self-hydration. Unrelated molecules of water may to hydrate of biomacromolecules, creating dense hydration shells around them. Hydration is the process of binding water chemicals - chemical reaction, which produces a new substance. Chemistry of biopolymers known that, for example, a protein with a molecular structure of amino acids have carboxyl $-\mathrm{COOH}$, hydroxyl $-\mathrm{OH}$ and amine $-\mathrm{NH}_{2}$ polar groups capable as a result 
of hydration attach up to $40 \%$ water by weight. [6] According to the teachings of Acad. V. Vernadsky bound water of hydration is an integral part of the protein. It naturally increases its mass, because it is connected to through the action of mechanisms similar to those that occur during its synthesis and almost equally well how strong peptide bonds. Food raw materials in today for the most part kept in the dried or frozen, that is, the loss of natural moisture or losing a bond with her. Therefore, finding the ability to manage the hydration of biopolymers solves a huge problem - reducing the number or excludes from food, nonfood substances, which are traditionally used to artificially increase the binding of water and in this way their mass.

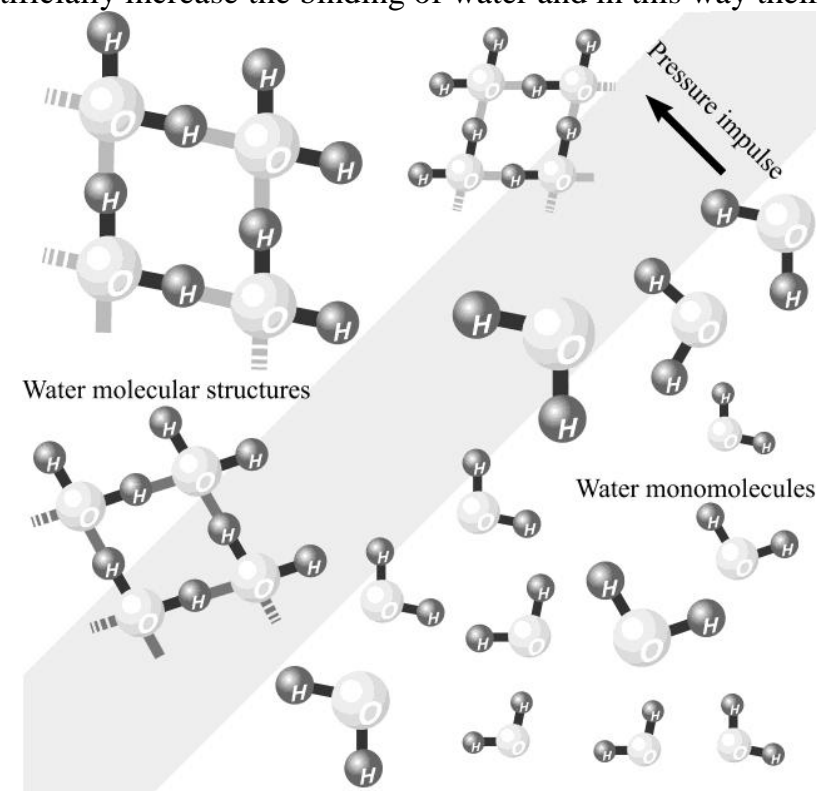

Fig 4. Scheme of destruction of molecular structure of water by cavitation

Hydration process management has become one of the main directions of development of food and drug sonochemistry in Russia [3]. Hydration capacity of water in relation to other substances depends on content in water of unstructured phase. When a source of energy of disintegration of the the hydrogen bonds is disappears, they again begin to recover in the amount corresponding to the thermodynamic equilibrium, returning the absorbed energy as heat self-hydrations. The hydrogen bonds disintegration by impulse of pressure cavitation occurs as is shown in figure:

$$
\mathrm{H}_{2} \mathrm{O}+\mathrm{H}_{2} \mathrm{O}+\ldots+\mathrm{H}_{2} \mathrm{O} \rightleftarrows m\left(\mathrm{H}_{2} \mathrm{O}\right)_{n}+25 \frac{n \cdot m}{N_{A}} k J
$$

where: $m$ - the number of molecular water associates in the reaction; $n$ - the number of water molecules is forming a stable associates; $N_{A}-$ Avogadro's number.

\section{REVIEW OF KNOWN METHODS ACTIVATION OF WATER}

Since the heat of vaporization of water is equal to $44 \mathrm{~kJ} / \mathrm{mol}$, then she may be to devoid of structure by heating. But if the goal is to increase the degree of hydration of biopolymers, which are themselves unstable to thermal denaturation, thermal fracture mechanism of hydrogen bonds is not acceptable. There are many known ways of destruction of the structure of water without her heating. These include all methods of mechanical action, such as processing in a colloid mill or in a disintegrator of rotary type, and sometimes transfer the energy using the polarity of water molecules [7]. A researcher working with the water is prepared by the last way for kneading dough on baking, found that thickness of the hydration shells of protein molecules is reduced and formed a more flexible structure of the protein. This supports the hypothesis of the structuring of protein by means hydration [8] (Fig 5).

These techniques improve the solvent power of water is doing by means changing her energy state at the expense of energy transformation different nature, temporarily deducing it from thermodynamic equilibrium. The advantage of sonochemical effect in is that the original chemical composition of the water does not matter. On the contrary, the water may contain dissolved in any amount or suspended solids and they will not be lost in the process of disintegration, as in the case of membrane cleaning and do not to form undesirable chemical compounds as at electrolysis. The latter is particularly important because for foods the content of mineral substances and the content of useful trace elements is controlled by dissolving them in incoming water. The cavitation in water is accelerate dissolution, ions of dissolved substances get the dense hydration shells, which reduces their ability to participate in unwanted chemical reactions. This is another advantage of sonochemistry. 


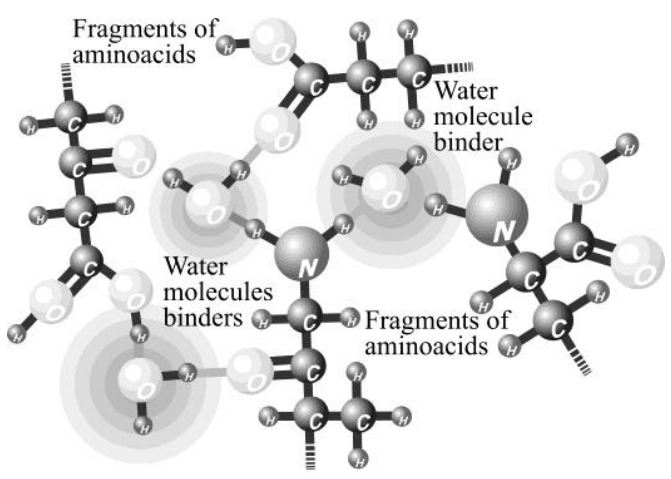

Fig 5. The structuring of protein by means hydration

Known a method of processing grain aqueous solution of propionic acid before placing it into storage [9] and the method of wetting grain with water (his conditioning) at production from it flour [10]. In these methods, the liquid is exposed to ultrasound. Acoustic processing power is not set explicitly, but in the second case is required to form hydroxyl ions and synthesis of hydrogen peroxide which is known to be implemented in two ways:

$$
\begin{aligned}
& \mathrm{OH}+\mathrm{OH} \rightarrow \mathrm{H}_{2} \mathrm{O}_{2} \\
& \mathrm{O}+\mathrm{HOH} \rightarrow \mathrm{H}_{2} \mathrm{O}_{2},
\end{aligned}
$$

where one of its part formed from of the synthesized hydroxyl ions, in the other is involved dissolved in the water oxygen [11]. Therefore in [10] is provided preliminary oxygen saturation of water by means forced aeration. The remaining hydroxyl ions in the water further destroy the structure of the grain due to the effect of ion cracking. A hydrogen peroxide has detrimental effect on the microflora and decomposed by enzymes of grain. Decomposition has explosive character, which also destroys the endosperm of kernels. But this method of preparation of water for hydration food stuff which include fats is not suitable, because they can oxidize, leading to a deterioration of taste and reduce the shelf life of products prepared from hydrated that way biomass. In Russia and Europe was patented a sonochemical method of hydration of proteins meat by water which processed in cavitation reactor at the amplitude of the sound pressure in the $2 \ldots 23$ times higher than the hydrostatic pressure in him [12]. This method is not widely adopted due to short shelf life of foods, such as sausages made with its use, even though it saves raw materials [13].

In MSUTM created the method sonochemical processing of brine [14] and sonochemical method of processing the water and water solutions to hydration biomass [15]. In they hydrogen peroxide is not synthesized in significant quantities, because the amplitude of the ultrasonic reactor pressure does not exceed twice the value of the hydrostatic pressure in the liquid. But the decrease of the pressure amplitude of ultrasound which causes cavitation and whose square of which is proportional the acoustic power of the process, has led to a drastic decrease of performance of the sonochemical processing. From the general physics we know that necessary for any action energy is equal to the product of the power of the impact on its duration. Therefore, such methods in the production of, for example, meat products have been used only in catering [13], where produced small quantities of products.

But there is a way of hydration of biopolymers by sonochemical processed water or solutions on its basis [16]. In it sonochemical processing carry out in the cavitational reactor with an average amplitude of sound pressure of the elastic wave exceeding hydrostatic pressure not less than in 5,5 times. In the description of this method examples of its implementation are given. In the first example at hydration of proteins of a gluten of grain of wheat is received the increase in weight of a crude gluten and reduction of the general microflora. It is known that the adipose component of the grain is in its embryo, which prior to processing of grain into flour is separated from the grains. Therefore, the method has shown here a positive result. In the second example sonochemical treatment of an aqueous suspension of mustard seeds to extract from it the substances used in the manufacture of mayonnaise, microbiological purity of the suspension medium and the content of organic acids in it increased. In the following example as a result of water processing for preparation of a brine at production semi-finished products from chopped meat the content of microflora in forcemeat decreased, fat - is increased. It is known that the analysis of the content of fat in foodstuff and semi-finished products is carried out methods of extraction by Soxhlet and Randall. Therefore it is possible to assume that the paradoxical increase in the content of fat in meat is connected with the increased extractability of products of its oxidation which formed at hydration by processed water. The given examples of implementation [16] confirm that oxidizers in water nevertheless are formed in sufficient quantities for oxidation of fats in a hydrated biomass. 


\section{HYPOTHESIS OF AN INTENSIFICATION OF SONOCHEMICAL PROCESSING OF WATER}

Problem of the last researches conducted by us is search of a way of decrease in the content in the processing water, including, which being the environment of solution or disperse system, oxidizers like hydrogen peroxide without decrease in acoustic power of the sonochemical processing, and without to reduction its productivity.

In [11] are given experimental data about $\mathrm{H}_{2} \mathrm{O}_{2}$ exit depending on the spent energy at synthesis by ultrasonic fluctuations. Noted, what hydrogen peroxide exit strongly depends on a chemical composition of water, in particular, from the content in it the dissolved oxygen of air. Later was a published result of researches about an exit the hydrogen peroxide in the two-factorial experiment [8]. By means of it it is established that this exit is optimized by function of two variables. Existence of a local maximum is explained with by heating of water from internal friction, decrease in the contents in it of oxygen and thermal decomposition at increase $\mathrm{H}_{2} \mathrm{O}_{2}$ in time of processing and acoustic power high over optimum values. It is known also that coincidence of collapse of cavitational bubbles practically any primary diameter in water from the end of the period of an acoustic wave which causing cavitation is comes with amplitude of pressure approximately equal to five hydrostatic pressure [13]. It is a so-called mode of sinperiodic cavitation. At increase above this value the potential energy responsible for the size of a cavitational erosion and a sonoluminescence both in singlebuibble and in multibubblle cavitation remains to constant, and the kinetic changes only. Thus, the mode of sinperiodic cavitation is most energetically favorable. But, as it was shown above, usage [16] in the food industry is hinder the education in hydrogen peroxide water in significant quantities. If to consider that the exit of hydrogen peroxide depends on the content in water of the dissolved oxygen of air, there was a hypothesis that is possible to lower it, previously having subjected water or water solution of deaeration.

\section{EXPERIMENTAL CONFIRMATION OF A HYPOTHESIS}

In [17] is described the fact of an invariance of permanganat oxidability of solutions of free organic acids, which is subjected sonochemical processing with an amplitude of acoustic pressure no more than 2 atm. Influence of processing on hydration ability of water was estimated there by efficiency of dissolution of tableted $\mathrm{NaCl}$. Therefore experimental check of correctness of this hypothesis it was carried out as follows.

Expenses of energy necessary on sonochemical water processing are established in [15]. At the room temperature they make about $2 \mathrm{~kW} \cdot \mathrm{h} / \mathrm{m}^{3}$. In reactor described in [17] is installed the magnetostriction converter with an electric power of $630 \mathrm{~W}$, its absolute productivity makes $0,16 \mathrm{~m}^{3} / \mathrm{h}$. Productivity of the reactor of the $\mathrm{Oil}$ Tech Production OY company (Tallinn) in [18], used in experiments (Fig 6), with piezoelectric converters is equal $1,08 \mathrm{~m}^{3} / \mathrm{h}$, that is amplitude of sound pressure here is 2,6 times more and is equal to amplitude of sinperiodic cavitation.

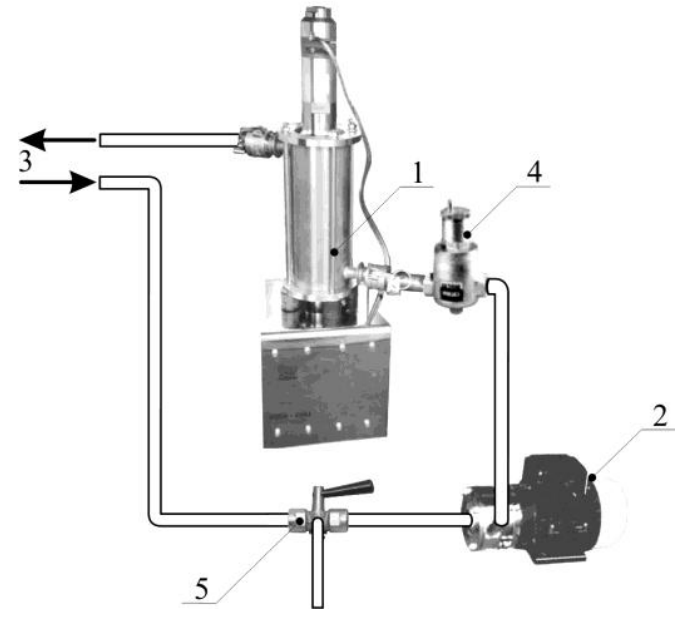

Fig 6. Experimental installation with the cavitational reactor of the company Oil Tech Production OY: 1 - reactor; 2 - pump; 3 - to a receiver; 4 -deaerator Caleffi 551; 5 -three-running crane.

Considering it, prepared three identical samples of solution of $0,4 m g /$ tannin which strongly predisposed to oxidation by hydrogen peroxide. The permanganat oxidability of solution measured by a method of Kubel, made 5,2 $\mathrm{mgO}_{2} / \mathrm{l}$. The first sample considered control and within $3 \mathrm{~min}$ in experimental installation recirculated it by means of the pump via the reactor which was disconnected, receiver and turning on deaerator after the pump. Method [16] was doing out on the second sample with recirculating of solution within $1 \mathrm{~min}$. The solution by means of the pump passed via the switched-on sonochemical reactor, a receiver and at the 
deaerator. Hypothesis checked on the third sample is processing it as follows: within 2 min solution recirculated by means of the pump via the switched-off sonochemical reactor, a receiver and deaerator, then for $1 \mathrm{~min}$ turned on the reactor. In all three cases after the expiration of time of processing the pump disconnected, the crane to solution plum and measured on ISO 8467 permanganate oxidability. In total five series of experiences were doing. Results are shown in the table in the form of average values with ranges of mean square deviations.

Table

\begin{tabular}{|l|c|c|c|c|}
\hline \multirow{2}{*}{ PARAMETER } & \multirow{2}{*}{ UNIT } & \multicolumn{3}{|c|}{ VALUE } \\
\cline { 3 - 5 } & & Sample 1 & Sample 2 & Sample 3 \\
\hline Permanganate oxidability & $m g O_{2} / l$ & $5,12 \pm 0,05$ & $2,31 \pm 0,07$ & $5,09 \pm 0,05$ \\
\hline
\end{tabular}

From the table it is visible that permanganate oxidability of samples 1 and 3 is almost identical whereas at a sample 2 it is lower. It means that the part of tannin was oxidized by the hydrogen peroxide formed in the course of sonochemical processing.

Further compared results of dissolution of the tablets $\mathrm{NaCl}$ during identical time by immersion them in the processed and non processed water (Fig 7). Results for sample 3 is similar to a photo from [17]. It is visible that the difference of reduction of volume of tablets dissolved in usual and to the sonochemical processed water is almost identical. But in a sinperiodic mode it was required to time for sonochemical processing much less.
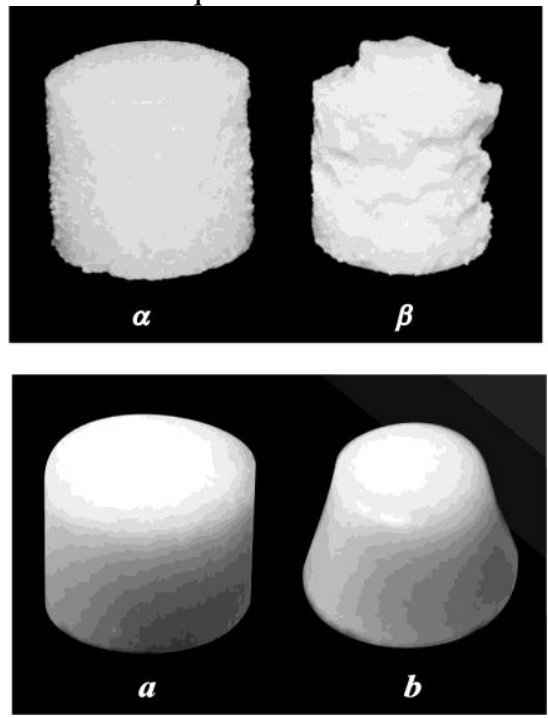

Fig 7. Tableted $\mathrm{NaCl}$ after exposure to normal water $a(\alpha)$ and water, subjected sonochemical processing $b(\beta)$ in accordance with [17] (top) and with [16], but with deaeration (bottom).

\section{CONCLUSION}

The experiments have confirmed the validity of the hypothesis, as the yield of hydrogen peroxide really depends on the content in the water of dissolved oxygen. This allows you to use in the food sonochemistry most energetically favorable mode the sinperiodic cavitation [13] subjecting the water or an aqueous solution of forced deaeration. At the same time hydration and solvent power of water can not fall off and time for sonochemical processing required less than traditionally accepted in food sonochemistry. That is use in the food industry the sonochemistry will be absolutely safe, if the take action which prevent the formation of hydrogen peroxide in water way remove from the solution atmospheric oxygen

\section{REFERENCES}

[1]. Taleyarkhan R. et al. Evidence for Nuclear Emissions During Acoustic Cavitation. Science, V.295, 2002, 1868-1873

[2]. Ashokkumar M., Rink R., Shestakov S. Hydrodynamic cavitation - an alternative to ultrasonic food processing. Electronic Journal “Technical Acoustics”, http://www.ejta.org, 2011, 9

[3]. Ashokkumar M. et al. A New Look at Cavitation and the Applications of Its Liquid-Phase Effects in the Processing of Food and Fuel. Applied Physics Research, Vol. 4, No. 1, 2012, 19-29

[4]. Margulis M. Basics sonochemistry. Chemical reactions in the acoustic field. (Moscow: High School, 1984) (in Russian)

[5]. Jinesh K. B., Frenken J. W. M. Experimental evidence for ice formation at room temperature. Physical Review Letters, 101, 2008, 036101.

[6]. Kuntz I.D. The physical properties of water bound to biomacromolecules, in R.B. Duckworth (Ed.) Water relations of foods (London: Academic Press, 1975) 
[7]. Korchagin V.I. et al. Use in baking temporarily activated water. Baking in Russia, 5, 2000, 16-18 (in Russian)

[8]. Shestakov S.D. Basics of cavitational disintegration. (Moscow: EVA press, 2001) (in Russian)

[9]. Patent RU 2122311, 1998

[10]. Patent RU 2171568, 2001

[11]. Flynn G. Physics of Acoustic Cavitation in Liquids, in W. Mason (Ed.) Methods and Devices of Ultrasonic Researches (V.1, Part B, New York, London: Academic Press, 1964)

[12]. Patent EP 1609368, 2007

[13]. Shestakov S. Food sonochemistry: concept, theoretical aspects and practical applications (Saarbrücken: LAMBERT Academic Publishing, 2012)

[14]. Patent RU 2402909, 2010

[15]. Patent RU 2444201, 2012

[16]. Patent application WO/2007/111524, 2007

[17]. Krasulya O.N., Shlenskaya T.V., Shestakov S.D. Experience using sonotechnology in the food industry, Proc. XXII Session of Russian Acoustic Society, Vol. 2, Moscow: GEOS, 2010 68-74

[18]. Rink R., Shestakov S., Babak V. The Sonochemical Reactors with Symmetric oscillatory Systems of the Acoustic Cells International Journal of Research and Reviews in Applied Sciences, Vol. 12, 3, 2012? 391-396 